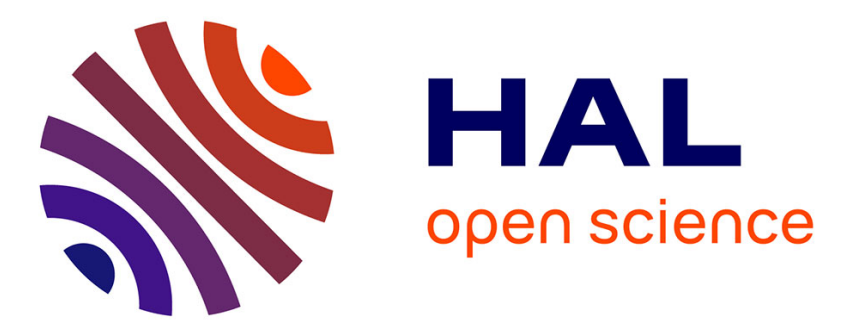

\title{
Rhizoctonia cerealis Van der Hoeven, agent du rhizoctone des céréales en France. Caractéristiques et variabilité
}

Philippe Lucas, Nadine Cavelier

\section{To cite this version:}

Philippe Lucas, Nadine Cavelier. Rhizoctonia cerealis Van der Hoeven, agent du rhizoctone des céréales en France. Caractéristiques et variabilité. Agronomie, 1983, 3 (9), pp.831-838. hal-00884578

\section{HAL Id: hal-00884578 \\ https://hal.science/hal-00884578}

Submitted on 1 Jan 1983

HAL is a multi-disciplinary open access archive for the deposit and dissemination of scientific research documents, whether they are published or not. The documents may come from teaching and research institutions in France or abroad, or from public or private research centers.
L'archive ouverte pluridisciplinaire HAL, est destinée au dépôt et à la diffusion de documents scientifiques de niveau recherche, publiés ou non, émanant des établissements d'enseignement et de recherche français ou étrangers, des laboratoires publics ou privés. 


\title{
Rhizoctonia cerealis Van der Hoeven, agent du rhizoc- tone des céréales en France. Caractéristiques et variabi-
} lité

Philippe LUCAS \& Nadine CAVELIER

I.N.R.A., Station de Pathologie végétale, Centre de Recherches de Rennes, F 35650 Le Rheu

RÉSUMÉ

\begin{abstract}
Le rhizoctone des céréales semble prendre de l'extension en France depuis quelques années. Des isolats obtenus à partir de nécroses sur gaines ou tiges sont comparés. S'ils appartiennent bien au genre Rhizoctonia, ils se différencient de $R$. solani par leur vitesse de croissance inférieure, la moins grande aptitude à former des sclérotes, le diamètre plus faible des hyphes mycéliens, des cellules binucléées et leur agressivité sur céréales. Ils peuvent être considérés comme appartenant à l'espèce $R$. cerealis. Une certaine variabilité est mise en évidence à l'intérieur de l'espèce, elle concerne la vitesse de croissance, l'aptitude à former des sclérotes et l'agressivité.
\end{abstract}

Mots clés additionnels : Souches, agressivité, Rhizoctonia solani, blé, orge, variétés. Characteristics and variability.

In France, it seems that sharp eyespot of cereals has been more frequently reported in recent years. Isolates obtained from lesions on leaf sheaths or culms of cereals belonged to the genus Rhizoctonia, but were different from $R$. solani. Only isolates from cereals were virulent on wheat and barley; they grew more slowly and produced less sclerotia than $R$. solani isolates; vegetative hyphae were narrower in diameter and cells were binucleate. Based on these characteristics, these isolates were assigned to $R$. cerealis. Variation has been shown in virulence, growth rate and sclerotial development within this species.

Additional key words : Strains, aggressiveness, Rhizoctonia solani, wheat, barley, cultivars.

\section{INTRODUCTION}

Signalé, semble-t-il, pour la première fois par SPRAGUE (1934) aux Etats-Unis, en Italie et Hongrie, le rhizoctone des céréales (ou « sharp eyespot ») a été considéré jusqu'à ces dernières années, en France, comme une maladie peu fréquente et non dommageable. Depuis peu toutefois, il est de plus en plus observé et si sa nuisibilité est encore controversée, cette extension inquiète.

A sa découverte, cette maladie est attribuée à Rhizoctonia solani Kühn. PITT (1964) montre que des isolats obtenus de tiges de blé sont agressifs sur blé, orge, avoine et seigle. Il ne trouve aucune différence de sensibilité parmi les variétés de blé inoculées. Il constate par contre, une grande variabilité des souches quant à leur agressivité. En 1967, ELNUR \& CHESTERS isolent, de blé, 2 souches de $R$. solani différant par leur morphologie et leur pouvoir pathogène. L'une présente un mycélium constitué de filaments plus larges, une vitesse de croissance plus rapide, n'attaque pratiquement que les parties aériennes et peut provoquer de graves dégâts sur fève à l'inverse de la seconde qui n'attaque que le blé, affecte surtout le système racinaire et la base des tiges. STERNE \& JONES (1978) isolent, de lésions caractéristiques sur tiges, plusieurs souches qu'ils rattachent à l'espèce $R$. solani. Ils en obtiennent également de racines ou du sol, mais seules les souches isolées de tiges reproduisent les symptômes sur celles-ci.

Auparavant, en 1977, BOEREMA \& VERHOEVEN, se basant sur des différences morphologiques et cytologiques, désignent le responsable du rhizoctone des céréales (« sharp eyespot ») sous le nom de Rhizoctonia cerealis Van der Hoeven. Cette espèce se caractérise par un mycélium à cellules binucléées (multinucléées chez $R$. solani), une vitesse de croissance et un diamètre des hyphés inférieurs à ce qu'ils sont chez $R$. solani.

Cette nouvelle dénomination d'espèce est acceptée par REINECKE \& FEHRMANN (1979) qui reproduisent aisément les symptômes sur blé avec des souches de $R$. cerealis et beaucoup plus difficilement avec des souches de $R$. solani.

HOFFMANN (1980) confirme les différences morphologi- 
ques et cytologiques entre $R$. solani et des isolats obtenus de blé atteint de «sharp eyespot». Toutefois, il considère, d'une part, que l'absence de spécialisation chez ces isolats (ils provoquent sur pomme de terre les mêmes symptômes que $R$. solani) interdit de leur donner le nom d'espèce cerealis et que, d'autre part, les différences observées entre ceux-ci et $R$. solani sont trop importantes pour leur donner le nom de genre Rhizoctonia. Se basant sur leur étroite ressemblance avec des isolats obtenus de gazon ( $«$ turf grass Rhizoctonia-like isolates ") également binucléés et généralement rattachés à la forme parfaite Ceratobasidium (SANDERS et al., 1978), il considère que le responsable du sharp eyespot est probablement une espèce du genre Ceratobasidium.

En fait, ce rattachement à la forme parfaite Ceratobasidium de Rhizoctonia binucléés inféodés aux Graminées n'est pas lié à une observation de leur forme sexuée (BURPEE, 1980). Ces isolats se classent de façon homogène dans le Groupe I des groupes d'anastomoses définis par BURPEE et al. (1980) et dénommés «Ceratobasidium Anastomosis Groups " (CAG) parce que quelques isolats du groupe 2 ont donné la forme parfaite Ceratobasidium. Par analogie, tous les «Rhizoctonia-like isolates » classés dans des groupes d'anastomose «CAG " sont considérés comme des espèces probables du genre Ceratobasidium. Pour BURPEE (1980), une telle approche est incorrecte et il identifie les " turf grass Rhizoctonia-like isolates" comme appartenant à l'espèce $R$. cerealis.

L'objectif de ce travail est de caractériser l'agent du rhizoctone des céréales en France et de préciser quelques aspects de sa biologie.

\section{MATÉRIEL ET MÉTHODE}

\section{A. Matériel}

Les différentes souches de Rhizoctonia étudiées dans le présent travail apparaissent dans le tableau 1, identifiées par un code (RC pour les souches isolées de céréales, RS pour les souches de $R$. solani). Y figurent également, lorsqu'elles sont connues, l'origine géographique de la souche, l'année d'isolement et la nature de la plante hôte (espèce-variété).

\section{TABLEAU 1}

Code et origine des isolats de $\mathrm{R}$. cerealis obtenus de nécroses à rhizoctone sur céréales et de ceux de $\mathrm{R}$. solani utilisés dans cette étude. Code and sources of isolates from sharp eyespot lesions on cereals and of $\mathrm{R}$. solani isolates tested in this study.

\begin{tabular}{|c|c|c|c|c|}
\hline \multirow[b]{2}{*}{$N^{\circ}$ Code } & \multicolumn{4}{|c|}{ Origine de l'isolat } \\
\hline & Plante & Variété & Année & Lieu (Département) \\
\hline $\mathrm{RC} 1$ & Blé & $?$ & 1967 & 29 Finistère \\
\hline $\mathrm{RC} 2$ & Blé & Roazon & 1980 & 36 Indre \\
\hline $\mathrm{RC} 3$ & Blé & Talent & 1980 & 02 Aisne \\
\hline RC 4 & Blé & Corin & 1981 & 51 Marne \\
\hline $\mathrm{RC} 5$ & Blé & Top & 1981 & 35 Ille-et-Vilaine \\
\hline $\mathrm{RC} 6$ & Blé & Lutin & 1981 & 51 Marne \\
\hline $\mathrm{RC} 7$ & Blé & Hardi & 1981 & 63 Puy-de-Dôme \\
\hline $\mathrm{RC} 8$ & Blé & Roazon & 1981 & 21 Côte-d'Or \\
\hline $\mathrm{RC} 9$ & Blé & Top & 1981 & 86 Vienne \\
\hline RC 10 & Blé & Lutin & 1981 & 77 Seine-et-Marne \\
\hline $\mathrm{RC} 11$ & Blé & Arminda & 1981 & 80 Somme \\
\hline RC 12 & Blé & $?$ & 1981 & 60 Oise \\
\hline $\mathrm{RC} 13$ & Blé & Lutin & 1981 & 77 Seine-et-Marne \\
\hline RC 14 & Blé & H 80 R 25 & 1981 & 35 Ille-et-Vilaine \\
\hline $\mathrm{RC} 15$ & Blé & $?$ & 1981 & 71 Saône-et-Loire \\
\hline RC 16 & Blé & $?$ & 1981 & 77 Seine-et-Marne \\
\hline RC 17 & Orge & Gerbel & 1981 & 80 Somme \\
\hline $\mathrm{RC} 18$ & Avoine & $?$ & $?$ & $?$ \\
\hline RS 1 & Betterave & $?$ & $?$ & $?$ \\
\hline RS 2 & Pomme de terre & $?$ & $?$ & $?$ \\
\hline RS 4 & Chou & $?$ & $?$ & $?$ \\
\hline RS 5 & Lin & $?$ & 1970 & 35 Ille-et-Vilaine \\
\hline RS 6 & Haricot & $?$ & 1981 & 29 Finistère \\
\hline RS 7 & Maïs & $?$ & 1981 & 85 Vendée \\
\hline
\end{tabular}

L'inoculation puis le suivi des symptômes sont effectués sur les variétés suivantes : « Lutin», « Roazon», « Hardi », " Capitole », "Rescler », "Marris Huntsmann », "Arminda », "Fidel ", "Talent " et «Top " pour le blé, «Astrix et Alpha » pour l'orge.

\section{B. Isolement}

Les isolements sont effectués à partir de fragments de gaines ou de tiges lavés soigneusement à l'eau du robinet puis dans l'eau stérile et séchés sur papier stérile avant d'être déposés sur un milieu gélosé à 2 p. 100 d'extrait de malt. Lorsque les échantillons sont souillés de terre, une désinfection superficielle est réalisée par immersion des fragments de tiges ou de gaines pendant 15 à $30 \mathrm{~s}$ dans l'alcool. Rincés dans l'eau stérile et séchés sur papier filtre stérile, ceux-ci sont alors découpés en petits fragments de 2 à $3 \mathrm{~mm}$ de long et placés sur le même milieu additionné d'antibiotiques (sulfate de streptomycine : $100 \mathrm{mg}$, pénicilline $\mathrm{G}$ sel de $\mathrm{K}: 50$ unités/l de milieu).

La température d'incubation est de $22^{\circ} \mathrm{C}$.

\section{Coloration des noyaux}

Le champignon est cultivé en boîtes de Petri sur milieu gélosé enrichi ou non à l'extrait de malt. Des explantats sont 
prélevés au front de croissance de la colonie et les noyaux colorés au bleu d'aniline à 0,5 p. 100 ou au bleu trypan à 0,2 p. 100 en solution acidifiée à $\mathrm{pH} 4$ par quelques gouttes d'HCl.

\section{Tests de croissance}

\section{En fonction de la température}

Les mesures de croissance en fonction de la température sont réalisées, sur milieu gélosé à l'extrait de malt en tubes inclinés, pour 3 souches isolées de blé.

Chaque tube est ensemencé avec un explantat calibré de $4 \mathrm{~mm}$ de diamètre prélevé au front de croissance d'une jeune colonie.

Cinq tubes pour chaque souche de champignon sont ensuite placés à l'obscurité, respectivement aux températures suivantes : $2,7,10,16,22,25,27,30$ et $37^{\circ} \mathrm{C}$. La vitesse de croissance est appréciée en mesurant quotidiennement la progression du front de croissance, la $1^{\text {ère }}$ mesure commençant $48 \mathrm{~h}$. après ensemencement.
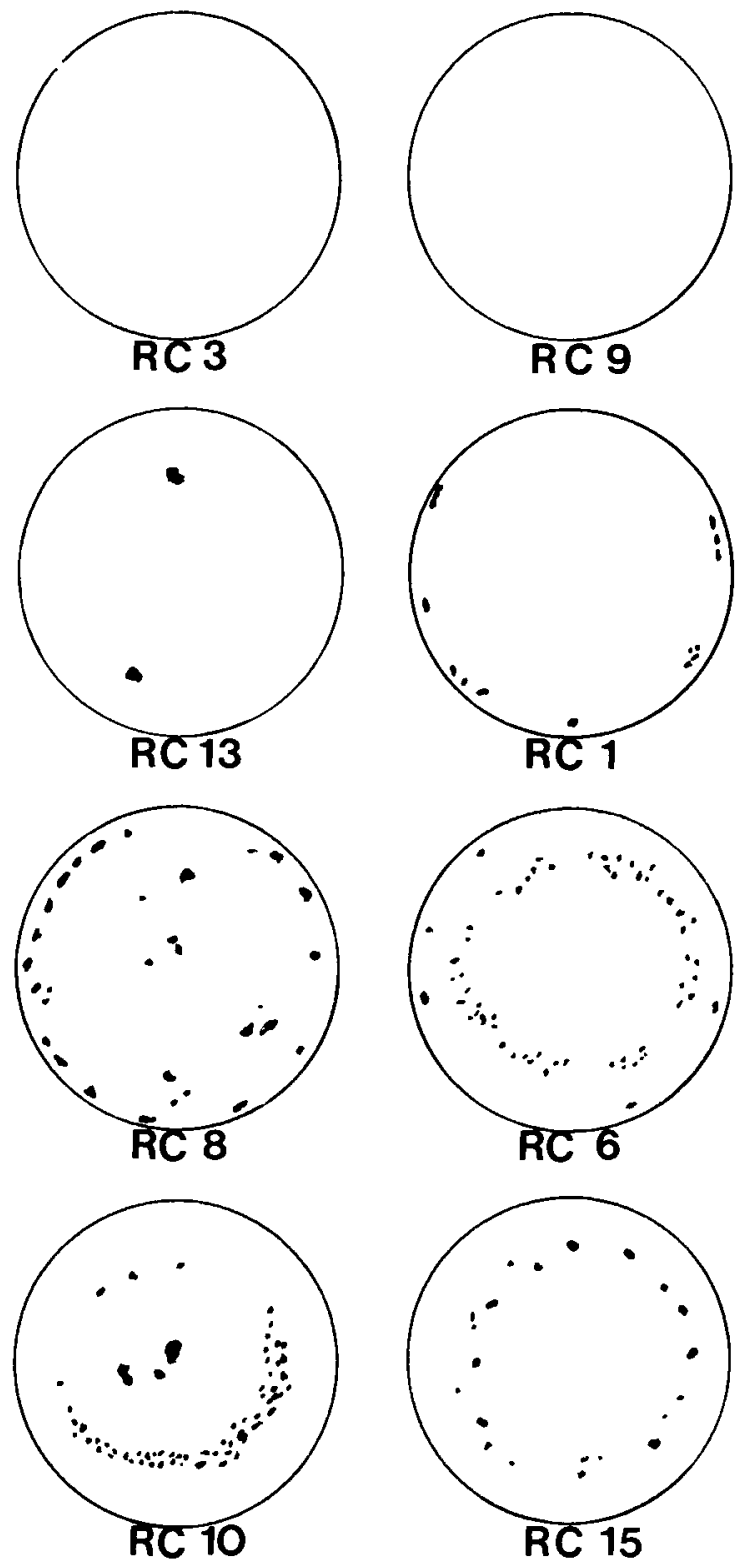

Figure 1

Formation de sclérotes chez différents isolats obtenus de blé atteint de rhizoctone $(R C)$ et chez 2 isolats de $\mathrm{R}$. solani $(R S)$ obtenus de chou et de lin après 2 mois de culture en boîte de Petri sur milieu gélosé à 2 p. 100 d'extrait de malt.

\section{Comparaison de différentes souches à leur optimum} thermique de croissance

La comparaison des vitesses de croissance de différentes souches isolées de blé à leur optimum thermique est réalisée en boîtes de Petri sur le même milieu en plaçant l'explantat au centre de la boîte et en mesurant quotidiennement selon 2 axes perpendiculaires, la progression du front de croissance de la colonie.

\section{E. Production d'inoculum et techniques d'inoculation}

Les différentes souches de Rhizoctonia sont multipliées sur grains d'orge, humidifiés par une quantité égale d'eau en poids et stérilisés par 2 passages à l'autoclave $\left(1 \mathrm{~h}\right.$ à $\left.120^{\circ} \mathrm{C}\right)$, à $24 \mathrm{~h}$. d'intervalle. Ce milieu, ensemencé, est mis à incuber 3 semaines à $22^{\circ} \mathrm{C}$. Les grains d'orges sont alors séchés à l'air libre.

L'inoculation consiste à déposer un grain d'orge ainsi colonisé au pied de chaque plante lorsqu'elles sont au stade 2 feuilles. Les tests d'inoculation sont effectués sur des
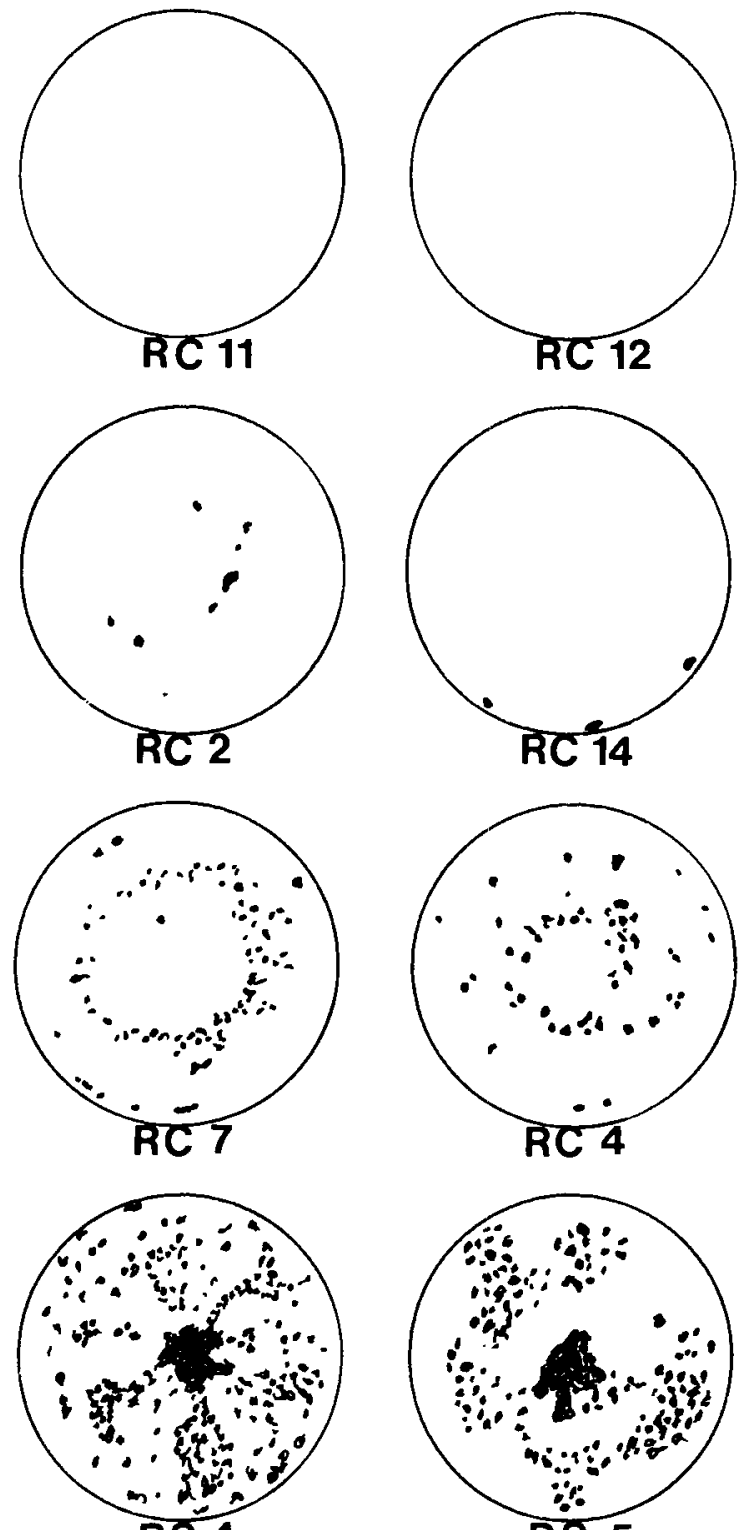

RS 4

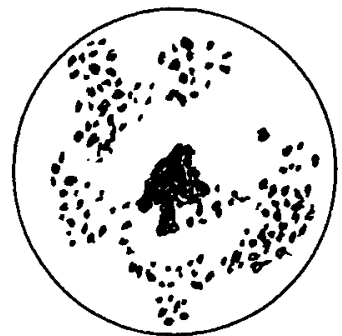

RS 5

Sclerotium formation by different isolates obtained from sharp eyespot lesions on wheat (RC) and by two isolates of $\mathrm{R}$. solani (RS) from cabbage and flax, after two months culture on malt extract-agar medium in Petri dishes. 
plantes en vase de végétation de 21 . contenant un mélange de terre, sable de rivière et tourbe en volumes égaux. Chaque vase reçoit 9 plantes. Les essais comprennent 5 répétitions et sont placés sous serre plastique à température ambiante, le seul contrôle thermique étant un dispositif anti-gel. Deux essais sont ainsi mis en place :

- l'un où l'agressivité de 12 isolats obtenus de blé et 6 isolats de $R$. solani est appréciée par inoculation de 2 variétés de blé, "Rescler», obtention de l'I.N.R.A. en cours d'inscription, et " Roazon ", choisie pour sa résistance au piétin verse, maladie affectant également la base des tiges.

- l'autre où la variabilité dans la manifestation de la maladie est recherchée parmi 10 variétés de blé et 2 variétés d'orge après inoculation avec 2 isolats obtenus de blé (RC2 et $\mathrm{RC} 4$ ).

\section{F. Critères de notation}

Des notations effectuées 40 et $90 \mathrm{j}$. après le semis portent sur le pourcentage de plantes présentant des attaques sur gaines, sans références à l'intensité des symptômes. Une dernière notation, $160 \mathrm{j}$. après semis, donne le pourcentage de plantes présentant des nécroses sur tiges.

\section{RÉSULTATS}

\section{A. Caractéristiques en culture}

44 isolats de Rhizoctonia, obtenus de céréales à paille (blé, orge, avoine) depuis 1967 et originaires de différentes régions de France, sont comparés.

En culture, sur milieu gélosé à l'extrait de malt, tous forment des colonies blanc jaunâtre, le mycélium pouvant être ras dans certains cas mais étant le plus souvent cotonneux. La formation de sclérotes est variable suivant les isolats. Sur ce milieu, certains n'en forment pas (RC3, RC9, $\mathrm{RC} 11, \mathrm{RC} 12$ ), d'autres, en forment beaucoup ( $\mathrm{RC} 4, \mathrm{RC} 7$ ) mais toujours en abondance moindre que les isolats de $R$. solani ( $\mathrm{RS} 4, \mathrm{RS5}$ ) (fig. 1) dont les colonies se différencient par leur couleur brune prononcée. L'observation microscopique confirme le diamètre supérieur des hyphes de $R$. solani (compris entre 5,5 et $11 \mu \mathrm{m}$ ) par rapport à ceux de $R$. cerealis (entre 2,8 et $5,5 \mu \mathrm{m}$ ).

\section{B. Nombre de noyaux}

Après coloration, 10 à 20 cellules sont observées pour chaque isolat et les noyaux dénombrés.

- Chez $R$. solani, les nombres de noyaux par cellule observée varient de 4 à 6 (moyenne 5) pour l'isolat RS4, 2 à 8 (moyenne 6) pour RS2, 4 à 8 (moyenne 6) pour RS6.

- Dans le cas de 15 isolats observés provenant de céréales, tous possèdent des cellules binucléées, qu'ils soient obtenus de nécroses sur blé, orge ou avoine (fig. 2).

Avec les techniques de coloration utilisées, les noyaux apparaissent plus nettement dans les cellules d'hyphes jeunes et sont plus faciles à observer sur les isolats provenant de céréales que sur ceux de $R$. solani.

\section{Courbe de croissance de 2 à $30^{\circ} \mathrm{C}$}

Dès $2^{\circ} \mathrm{C}$, la croissance mycélienne de 3 isolats ( $\mathrm{RC} 2$, $\mathrm{RC4}, \mathrm{RC} 11)$ issus de blé est déjà sensible ; la vitesse augmente ensuite régulièrement jusqu'à $22^{\circ} \mathrm{C}$ qui constitue l'optimum, pour diminuer rapidement au-delà de cette température et devenir nulle à $30^{\circ} \mathrm{C}$ (fig. 3 ). A l'optimum

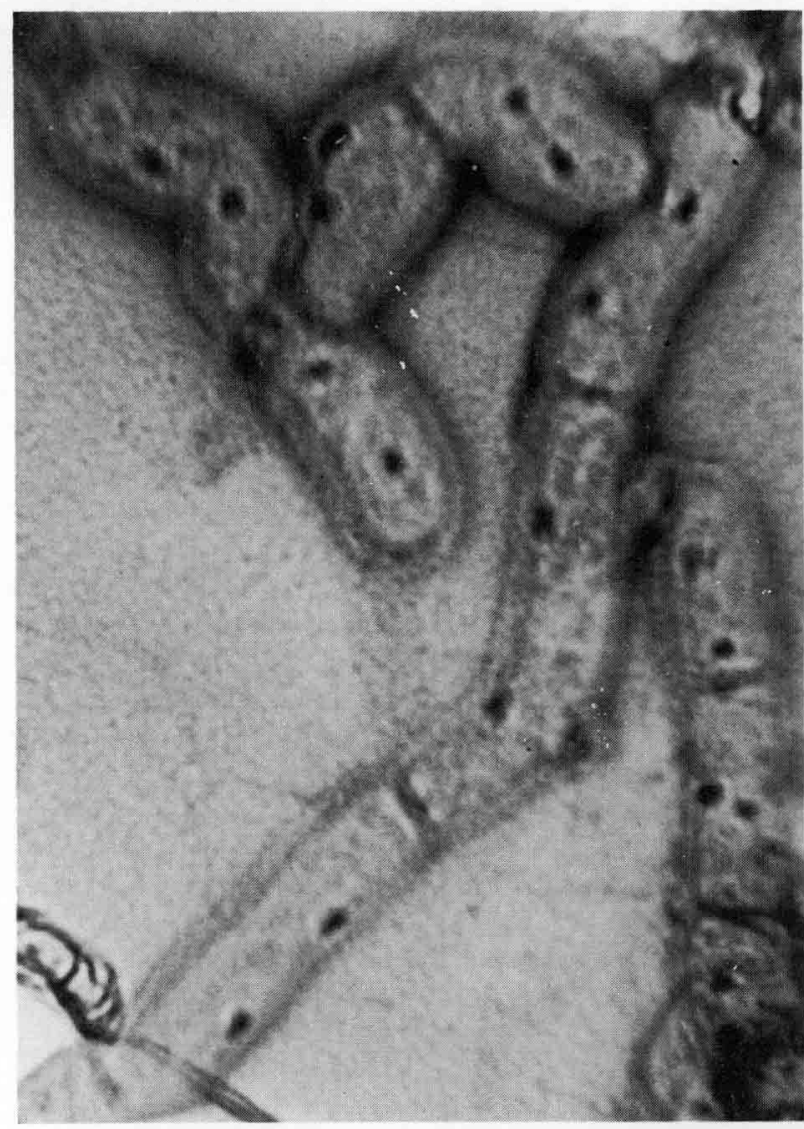

Figure 2

Cellules binucléées d'hyphes de Rhizoctonia isolé de céréales (R. cerealis).

Binucleate cells in hyphae of Rhizoctonia isolated from cereals (R. cerealis).

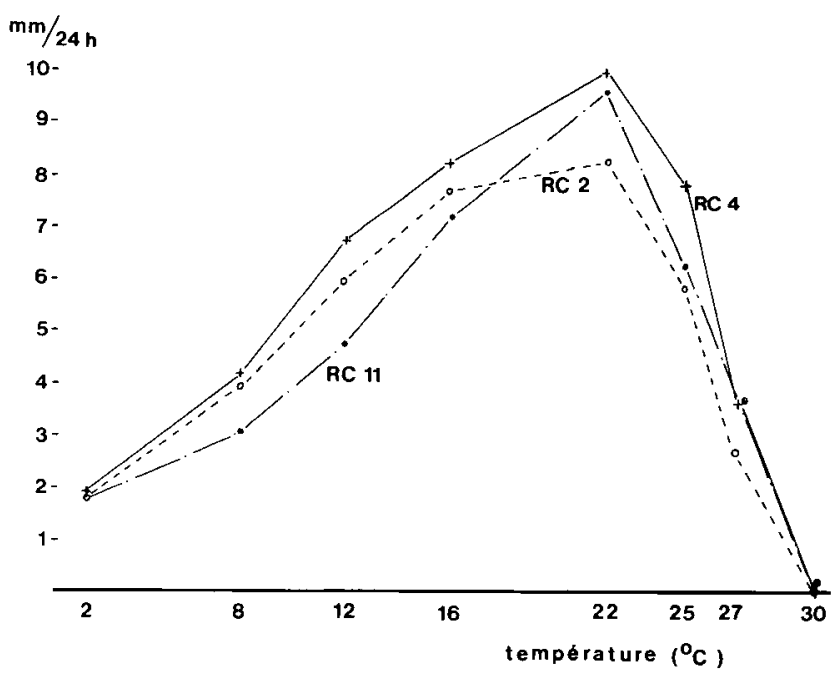

Figure 3

Vitesse de progression du front de croissance de 3 isolats $R C 2, R C 4$ et $R C 11$, sur milieu gélosé à l'extrait de malt, en fonction de la température.

Relation between growth rates of three isolates $R C 2, R C 4$ and $R C 11$ on malt extract agar medium and temperature.

thermique, la vitesse de croissance de ces 3 isolats varie de 8,2 à $9,9 \mathrm{~mm}$ par $24 \mathrm{~h}$. et, à $2^{\circ} \mathrm{C}$, elle représente 20 p. 100 de ce qu'elle est à $22^{\circ} \mathrm{C}$. 


\section{Vitesses de croissance de différents isolats à $22^{\circ} \mathrm{C}$}

Les vitesses de progression du front de croissance de la colonie mesurées sur 16 isolats obtenus de blé, orge et avoine (tabl. 2) montrent une certaine variabilité entre les isolats les plus « lents » $(7,3 \mathrm{~mm} / 24 \mathrm{~h})$ et les plus « rapides » $(10,3)$. Les valeurs obtenues avec les souches de $R$. solani isolées de chou (RS4) et de lin (RS5) sont respectivement de 15 à $20 \mathrm{~mm}$ par $24 \mathrm{~h}$.

\section{TABLEAU 2}

$V$ Vitesse de progression du front de croissance des colonies de 16 isolats de $\mathbf{R}$. cerealis obtenus de blé $(R C)$ et de 2 isolats de $\mathbf{R}$. solani (RS) provenant de chou et de lin à $22^{\circ} \mathrm{C}$ sur milieu gélosé à l'extrait de malt (en $\mathrm{mm}$ par $24 \mathrm{~h}$ ).

Growth rates of 16 isolates from wheat and $2 \mathrm{R}$. solani isolates from cabbage and flax, incubated at $22^{\circ} \mathrm{C}$ on malt extract-agar $(\mathrm{mm} / 24 \mathrm{~h})$.

\begin{tabular}{lclc}
\hline \hline Isolats & $\begin{array}{c}\text { Croissance } \\
\text { en mm/j }\end{array}$ & Isolats & $\begin{array}{c}\text { Croissance } \\
\text { en mm } / \mathrm{j}\end{array}$ \\
\hline RC 8 & 10,3 & RC 16 & 8,7 \\
RC 7 & 10,1 & RC 5 & 8,6 \\
RC 4 & 9,8 & RC 11 & 8,5 \\
RC 10 & 9,4 & RC 13 & 8,3 \\
RC 9 & 9,2 & RC 6 & 8,2 \\
RC 14 & 9,1 & RC 3 & 7,4 \\
RC 15 & 8,8 & RC 2 & 7,3 \\
RC 1 & 8,8 & RS 4 & 15 \\
RC 12 & 8,8 & RS 5 & 20 \\
\hline
\end{tabular}

\section{E. Variabilité dans l'évolution des symptômes en fonction des souches}

On observe que les souches les plus agressives aux jeunes stades de la plante comme $\mathrm{RC} 11$ et $\mathrm{RC} 12$ provoquent peu ou pas de symptômes sur les tiges. A l'inverse, une souche comme RC6, qui ne provoque aucun dégât apparent à la $1^{\text {ère }}$ notation, se révèle la plus agressive sur tiges. Les souches de $R$. solani, dans ces conditions d'expérimentation, n'ont montré qu'une très faible agressivité sur blé (fig. 4).

Si l'on compare les coefficients de tallage, on constate que, parmi les 4 souches ayant significativement affecté le tallage, figurent les 2 souches ( $\mathrm{RC} 11$ et $\mathrm{RC} 12$ ) les plus agressives aux stades jeunes. Cette réduction est due à une mortalité des talles formées. Signalons un effet positif sur le tallage à la suite de l'inoculation avec la souche RS2 de R. solani (tabl. 3).

\section{F. Variabilité dans la réponse de quelques génotypes de blé}

Pour une même époque de notation et quelle que soit la variété, l'inoculation avec la souche $\mathrm{RC} 4$ entraîne des pourcentages de plantes atteintes non significativement différents. Par contre, on observe après inoculation avec la souche RC2 des différences importantes de ces pourcentages selon les variétés (fig. 5).

En fonction de l'époque de notation, on constate que pour une même souche l'évolution des symptômes, après inoculation avec la souche $\mathrm{RC} 2$, peut être différente selon les variétés. Ainsi «Lutin», fortement attaqué au stade jeune sur gaines, présente relativement peu de symptômes sur tige alors que "Top», " Fidel» et «Talent ", qui ne présentent pas de symptômes à la $1^{\text {ère }}$ notation, manifestent

\section{TABLEAU 3}

Coefficients de tallages observés sur la variété "Rescler" après inoculation avec 12 isolats obtenus de blé $(R C)$ et 6 isolats de R. solani (RS). (Les valeurs suivies de lettres différentes sont significativement différentes pour $p .=0,05$ ) (Seules les talles vivantes sont comptées).

Tillering of wheat ( $c v$ "Rescler $\gg)$ when inoculated with 12 isolates from wheat $(R C)$ and $6 \mathrm{R}$. solani isolates $(R S)$. (Values followed by different letters are significantly different at $p .=0.05)$. (Only alive tillers have been counted).

Inoculation avec

Coeff. de tallage

\begin{tabular}{lll}
\hline RC 12 & 1,24 & a \\
RC 11 & 1,27 & a \\
RC 2 & 1,50 & ab \\
RC 4 & 1,56 & ab \\
RC 17 & 1,56 & abc \\
RC 8 & 1,60 & abc \\
RC 16 & 1,60 & abc \\
RC 1 & 1,66 & bc \\
RC 7 & 1,73 & bcd \\
RC 9 & 1,85 & bcde \\
RC 6 & 1,90 & cde \\
Pas d'inoculation & 1,90 & cde \\
RS 1 & 2,07 & def \\
RS 7 & 2,08 & def \\
RS 5 & 2,15 & ef \\
RC 5 & 2,16 & ef \\
RS 6 & 2,17 & ef \\
RS 4 & 2,18 & ef \\
RS 2 & 2,41 & f \\
\hline
\end{tabular}

les plus fortes attaques sur tige à la dernière (respectivement 57, 31 et 34 p. 100 de tiges nécrosées).

On retrouve, dans cet essai, confirmation de la plus grande propension de la souche $\mathrm{RC} 2$ à provoquer des attaques sur tiges que la souche RC4.

\section{DISCUSSION-CONCLUSION}

\section{A. $R$. cerealis, agent du rhizoctone des céréales}

Pour Parmeter \& Whitney (1965), un champignon possédant un mycélium binucléé ne peut être rattaché à l'espèce $R$. solani.

En ce qui concerne nos isolats obtenus de blé, orge ou avoine, ils se différencient tous des souches de $R$. solani de notre collection par:

- leur vitesse de croissance inférieure,

- la couleur blanchâtre et non brune de leurs colonies,

- le diamètre plus faible du mycélium,

- la plus faible production de sclérotes.

S'il existe, sur certaines de ces caractéristiques, une variabilité d'un isolat à l'autre, elle est faible par rapport aux différences observées entre ceux-ci et les isolats de $R$. solani. D'autre part, sur 15 isolats de céréales observés, tous ont un mycélium à cellules binucléées. Le champignon responsable du rhizoctone des céréales n'est donc pas $R$. solani. Par contre, l'existence du pore proéminent sur la cloison de séparation des cellules, la présence de ramification près du septum diśtal des cellules chez les jeunes hyphes, la formation d'un septum dans les ramifications près de leur point d'origine, la formation de cellules monilioïdes et de sclérotes constituent des critères (PARMETER \& WHITNEY, 1965) qui permettent de rattacher ce champignon au genre Rhizoctonia. Bien que nous n'ayons pas montré sa spécificité vis-à-vis des céréales, il paraît évident que nous sommes en présence du même type de 

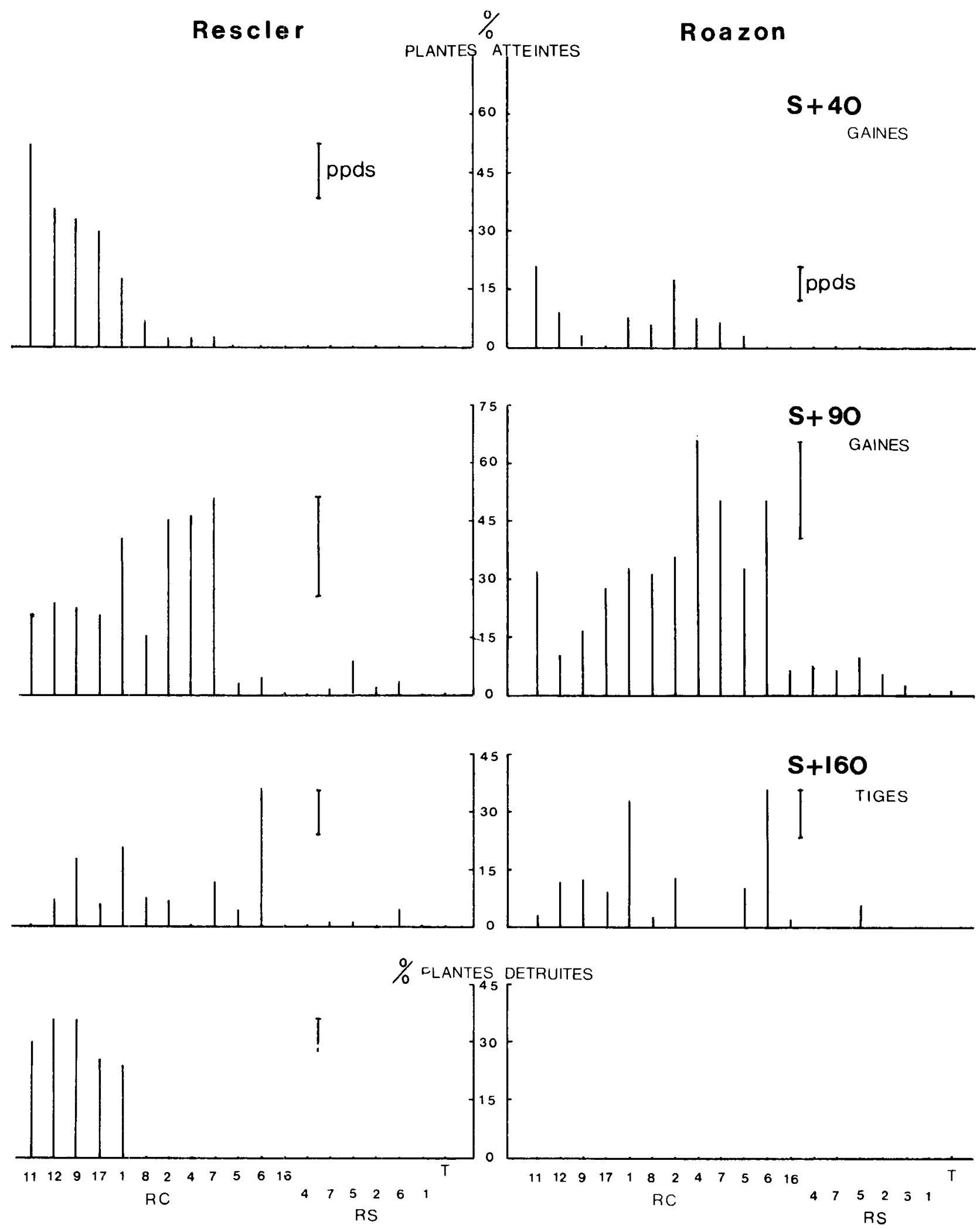

ISOLATS

Figure 4

Evolution du pourcentage de plantes vivantes atteintes après inoculation avec différents isolats obtenus de céréales $(R C)$ et $\mathrm{R}$. solani $(R S)$ ou sans inoculation $(T)$ et pourcentages de plantes détruites par rapport aux plantes levées lors de l'inoculation (ppds calculée pour $p .=0,05)$. Les notations sont effectuées 40,90 et $160 \mathrm{j}$. après semis $(S+40, S+90$ et $S+160)$.
Percent of surviving diseased plants after inoculation with different isolates from cereals $(R C)$ and $\mathrm{R}$. solani $(R S)$ or without inoculation $(T)$, and percent of killed plants relative to emergence at inoculation time (L.S.D. calculated at p. $=0.05)$. Assessments made 40, 90 and 160 days $(S+40, S+90, S+160)$ after sowing date. 


\section{Inoculation avec}
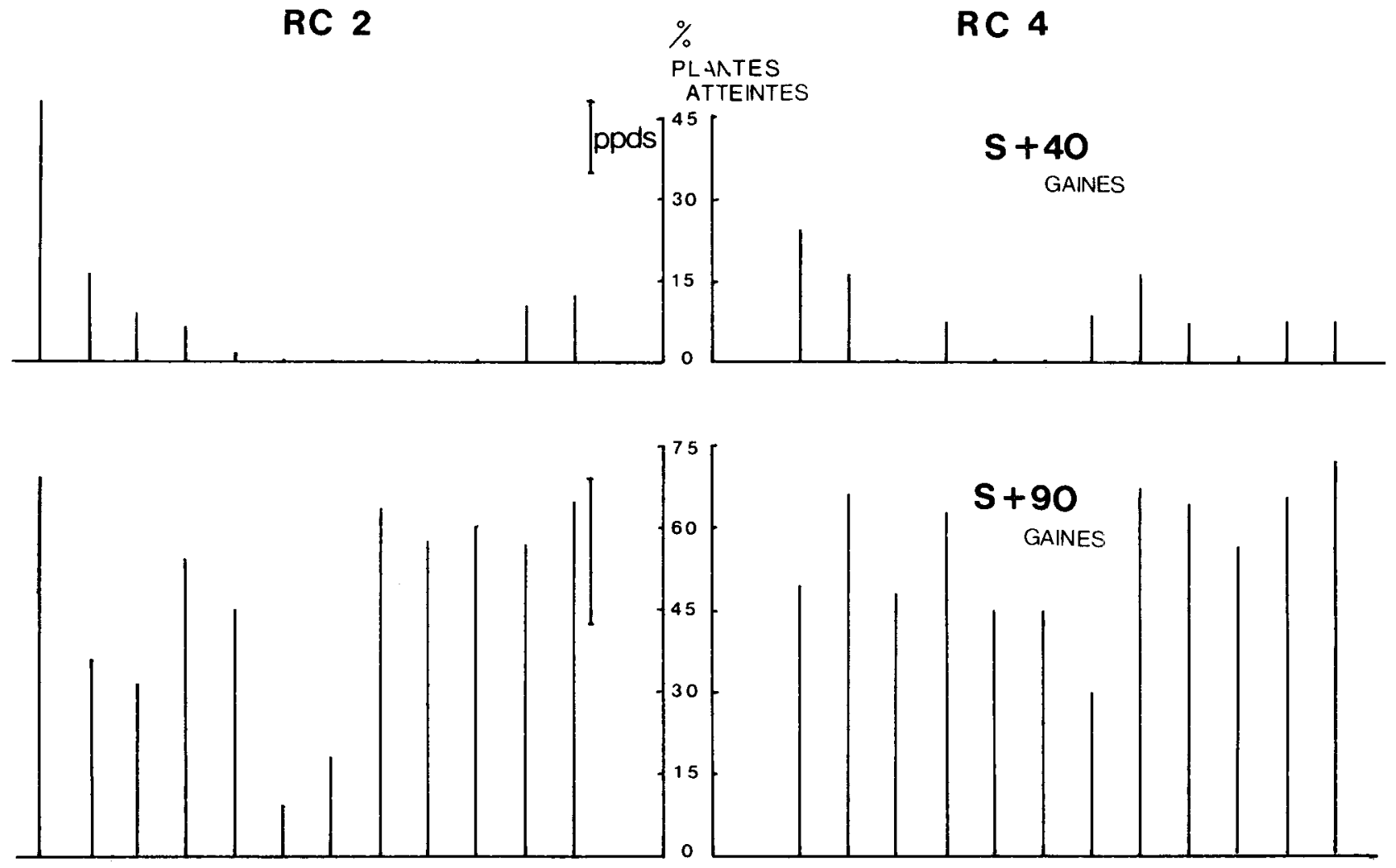

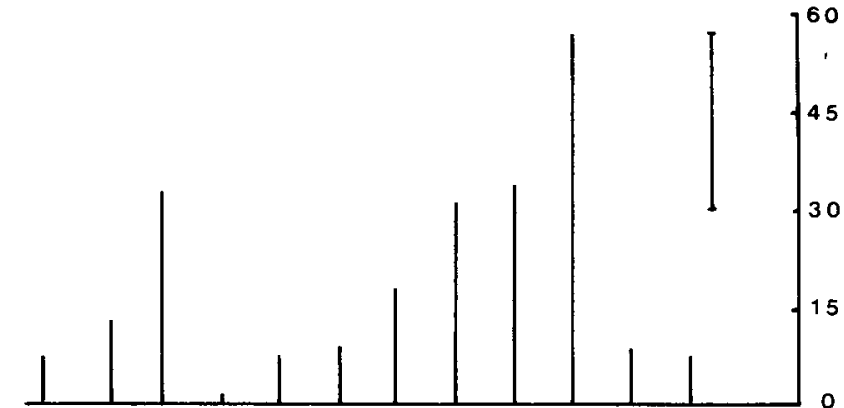

Lu Ro Ha Ca Re Mh Ar Fi Ta To As A
$S+160$

TIGES
Figure 5

Evolution $d u$ pourcentage de plantes atteintes chez différentes variétés de blé et d'orge après inoculation avec 2 isolats obtenus de blé atteint de rhizoctone; (ppds calculée pour $p .=0,05)$. Les notations sont effectuées 40,90 et $160 j$. après semis $(S+40, S+90$ et $S+160)$.

Percent of diseased plants within different cultivars of wheat and barley, after inoculation with two isolates obtained from wheat with sharp eyespot symptoms. (L.S.D. calculated at p. $=0.05)$. Assessments have been made 40, 90 and 160 days after sowing date $(S+40$, $S+90, S+160)$.

Blé (wheat): "Lutin» (Lu), «Roazon» (Ro), "Hardi» (Ha), "Capitole" (Ca), "Rescler » (Re), "Marris Huntsmann" (Mh), «Arminda» (Ar), «Fidel » (Fi), «Talent » (Ta), «Top» (To). Orge (barley) : "Astrix" (As), "Alpha» (Al). 
champignon que celui décrit par BOEREMA \& VERHOEVEN (1977), c'est-à-dire de $R$. cerealis.

Enfin, sur les 120 isolements répertoriés, effectués au cours des années 1981 et 1982 à partir de nécroses de rhizoctone sur gaines ou tiges, tous ont révélé la présence de champignons du type $R$. cerealis (d'après la vitesse de croissance, la couleur de la colonie sur milieu à base de malt, l'aptitude à former des sclérotes). Si $R$. solani avait été présent sur de telles nécroses, il aurait été isolé puisque sa vitesse de croissance est supérieure à celle de $R$. cerealis et que in vitro, les 2 champignons poussent très bien ensemble sur un même milieu.

On peut donc affirmer que $R$. cerealis est bien l'agent du rhizoctone («sharp-eyespot») des céréales observé en France. Jusqu'à présent, il n'a jamais été signalé et nous n'avons jamais observé d'attaques sur racines dues à un champignon du genre Rhizoctonia.

\section{B. Variabilité chez $R$. cerealis}

Si $R$. cerealis est une espèce aux caractéristiques assez homogènes, très différente de $R$. solani, nous avons néanmoins pu mettre en évidence une certaine variabilité entre les souches étudiées. Outre la vitesse de croissance et la faculté de former des sclérotes sur un milieu à l'extrait de malt, la variabilité dans l'expression et l'évolution des symptômes soulève un certain nombre de questions. Ces observations ont, en effet, été effectuées en conditions semi-contrôlées avec des températures descendant exceptionnellement au-dessous de $2{ }^{\circ} \mathrm{C}$, jamais en dessous de $0{ }^{\circ} \mathrm{C}$. Observe-t-on aussi au champ des attaques précoces dès le stade 3-4 feuilles susceptibles de provoquer des cas de mortalité ? La non-évolution, parfois observée au champ, de fortes attaques sur gaines en symptômes sur tiges, est-elle due à l'incapacité de la souche ou des souches présentes à induire de tels symptômes, à la variété peu susceptible d'être attaquée à ce stade ou à des conditions climatiques peu propices au développement de la maladie ?

Le suivi au. champ de plantes en conditions normales de culture et inoculées avec différentes souches, un inventaire des types de souches existant dans une parcelle à différents stades d'une culture de blé seraient nécessaires pour apporter des éléments de réponse à ces questions.

Reçu le 27 février 1983. Accepté le 28 avril 1983.

\section{RÉFÉRENCES BIBLIOGRAPHIQUES}

Boerema G. H., Verhoeven Adriana A., 1977. Check-list for scientific names of common parasitic fungi. Ser. $2 b$ : Fungi on field crops : cereals and grasses, Neth. J. Plant Pathol., 164-204.

Burpee L. L., 1980. Rhizoctonia cerealis causes Yellow Patch of Turfgrasses, Plant Dis., 64, 1114-1116.

Burpee L. L., Sanders P. L., Cole H. Jr, Sherwood R. T., 1980. Anastomosis groups among isolates of Ceratobasidium cornigerum and related fungi. Mycologia, 72, 689-701.

Elnur E., Chesters C. G. C., 1967. A note on two isolates of Rhizoctonia solani Kühn from wheat. Plant Pathol., (16), 104-107.

Hoffmann G. M., 1980. « Rhizoctonia " ähnliche Pilze und Rhizoctonia solani Kühn (Thanatephorus cucumeris (Frank) Donk.) an Getreide. Z. Pflkrankh. Pflschutz, 87 (5/6), 317-327.

Parmeter J. R. Jr., Whitney H. S., 1965. Taxonomy and nomenclature of the imperfect state, p. 7-19 ... J. R. Parmeter Jr. : Rhizoctonia solani, biology and pathology. Univ. Calif. Press, $255 \mathrm{p}$.
Pitt D., 1964. Studies on sharp eyespot disease of cereals. I. Disease symptoms and pathogenicity of isolates of Rhizoctonia solani Kühn and the influence of soil factors and temperature on disease development. Ann. appl. Biol., 54, 77-89.

Reinecke P., Fehrmann H., 1979. Rhizoctonia cerealis Van der Hoeven an Getreide in der Bundesrepublik Deutschland. Z. Pflkrankh-Pflschutz, 86 (3/4), 190-204.

Sanders P. L., Burpee L. L., Cole H., 1978. Preliminary studies on binucleate turfgrass pathogens that resemble Rhizoctonia solani. Phytopathology, 68, 145-148.

Sprague R., 1934. Preliminary note on another foot rot of wheat and oats in Oregon. Phytopathology, 24, 946-948.

Sterne R. E., Jones J. P., 1978. Sharp eyespot of wheat in Arkansas caused by Rhizoctonia solani. Plant Dis. Rep., 62, 56-60. 